\title{
FICCIONES DOCUMENTALES: EXCESO AFECTIVO Y SURGIMIENTO DE LA FICCIÓN EN FOTOGRAFÍAS, DE ANDRÉS DI TELLA
}

\author{
POR \\ LuZ Horne \\ Universidad de San Andrés, Argentina
}

En una entrevista de hace ya algunos años, Sergio Chejfec se refiere al motivo del viaje en la literatura contemporánea como una excusa para construir una estructura que la haga posible:

El viaje, si quiere ser representado por la literatura, se ha convertido en una especie de murmullo, una reflexión alrededor de los detalles y las variaciones del mundo. Precisamente, eso hace que viajar no sea necesario, que se pueda considerar un viaje como una vuelta a la manzana. El viaje se ha transformado, como otro tipo de relato, en una especie de matriz vacía y, por lo mismo, sumamente rica. Se lo puede tomar como una excusa perfecta para hablar de muchas cosas al mismo tiempo. Eso es lo bueno que tiene, creo, la literatura contemporánea. Que todo es una excusa para ella. (Hounie, énfasis mío)

Según esta inflexión, el viaje, ya despojado de cualquier tipo de épica, surge como un pretexto para construir una obra que agrupa temas heterogéneos. Pero así como el viaje - dice Chejfec- cualquier tema puede tomarse como un motivo "para hablar de muchas cosas al mismo tiempo", para agrupar asuntos que no tienen que ver entre sí, para la reflexión. El texto literario se transforma así en un gran repositorio o en un archivo en el que se guardan observaciones, pensamientos o relatos de experiencias cotidianas, y el viaje aparece como una de las tantas formas de otorgarle a la obra una unidad que es, sin embargo, muy leve: apenas un murmullo. En una entrevista a propósito de la aparición de su novela Borgestein (2012), Sergio Bizzio también alude a algo similar al expresar su deseo de escribir un texto en el cual el registro de diversos "estados mentales" sea el centro de la obra:

Si tuve alguna intención consciente fue la de seguir al protagonista en su reclusión. Quería escribir una novela sin sujeto, una novela que fuera más que nada el registro 
de una serie de estados mentales. Un texto de observación, de detalles, de minuncias, de pequeñas cosas insignificantes y corrientes. Una novela donde no pasaran grandes cosas. (Erlan)

Tanto en la observación de Chejfec como en la de Bizzio se hace evidente una característica que se repite de un modo llamativo en muchos textos actuales: la posibilidad que tiene la literatura contemporánea de construirse a partir de un cierto vacío o de una ausencia de tramas sólidas o intrigas complicadas. Así como muchas veces se acude al viaje como "excusa", en otras ocasiones se buscan diferentes temas que brindan una estructura coherente, pero que permiten una amplitud suficiente como para asegurar una cierta volatilidad (el murmullo) o libertad en cuanto a la posibilidad de digresión y de reflexión sobre el propio proceso de escritura. Una literatura en la que "no pasen grandes cosas" o un "discurso vacío", para citar el título de una novela de Mario Levrero, uno de los textos que podrían ser considerados como parte de esta constelación. ${ }^{1}$ Los ejemplos son muchos, pero entre ellos podrían citarse algunos textos de Mario Bellatín, Sergio Chejfec, Laura Erber, Reinaldo Laddaga, Mario Levrero, Valeria Luiselli, Eduardo Lalo, Nuno Ramos, Martín Rejtman, Cynthia Rimsky, Tatiana Salem-Levi, Paloma Vidal o Alejandro Zambra. ${ }^{2}$ Se trata de textos cuyo estatuto ficcional no es evidente, en parte debido a esta levedad en la organización de la trama y al alto grado de reflexividad que los caracteriza, pero también porque son textos en los que se suelen incluir ciertas referencias a la figura del autor, ya sea como narrador o como personaje. Esta inclusión establece una marca indicial en el texto que enfatiza la dificultad de clasificarlos en un único registro: ¿se trata de ficciones?, ¿son crónicas?, ¿son ensayos?, ¿son autobiografías?

La pregunta no es fácil de responder porque los textos se sostienen precisamente en función de esta ambivalencia o vacilación entre lo documental y lo ficcional; entre lo literario y lo que no lo es. Incluso, se podría pensar que este tipo de textos se insertan dentro de una tendencia más generalizada en el panorama cultural contemporáneo en

1 En esta novela, escrita en forma de diario, el narrador (identificado con Mario Levrero) decide hacer una "autoterapia" conductista: escribe a mano intentando mejorar su caligrafía, para que, al no poner atención en el contenido de lo que escribe, la mejora caligráfica tenga como resultado una mejora en su conducta. Lo que me interesa subrayar es la falta de énfasis en el contenido de lo que se escribe, no porque esto implique prestarle una atención desmesurada a la forma -esta ya no es la oposición relevante-sino porque la vacuidad permite generar una libertad en el ejercicio de la escritura y darle un lugar a la digresión y a la reflexión: "Hay un fluir, un ritmo, una forma aparentemente vacía; el discurso podría tratar cualquier tema, cualquier imagen, cualquier pensamiento" (Levrero 53).

2 La cantidad de obras que trabajan en este mismo registro es inmensa, con lo cual este listado pretende ser sólo ilustrativo y, de ningún modo, exhaustivo. Por otro lado, aquí me estoy refiriendo únicamente a un contexto latinoamericano no porque crea que el recorte es conceptualmente relevante en este momento contemporáneo y para este problema en particular, sino por una cuestión de imposibilidad real de abarcar un panorama global.

Revista Iberoamericana, Vol. LXXXII, Núm. 257, Octubre-Diciembre 2016, 837-854 ISSN 0034-9631 (Impreso)

ISSN 2154-4794 (Electrónico) 
la que las divisiones entre disciplinas artísticas caen y se produce una imbricación de diferentes medios y formas de expresión artística. ${ }^{3}$ Esta nueva configuración cultural -y los desafíos que ella presenta para los críticos culturales- ha sido pensada desde diversos ángulos en la crítica latinoamericana. Josefina Ludmer habla de una literatura posautónoma y de un nuevo modo de imaginación para el presente. Según ella, las nuevas escrituras entran y salen de la realidad a la literatura y viceversa, y se constituyen en esa "ambigüedad" en donde ya no se puede hablar de "realidad" o "ficción" sino de "realidadficción" (Ludmer, Aquí América). Jean Franco habla de la caída de la ciudad letrada, Néstor García Canclini habla del "arte fuera de sí", Florencia Garramuño de una obra "estriada por el exterior" y Reinaldo Laddaga se propone indagar qué formas son las que corresponden a una cultura no disciplinaria de las artes (Estética). Según este crítico, el escenario artístico contemporáneo presenta un cambio tan drástico y produce una modificación tan importante en cuanto a la concepción de la literatura misma, que puede compararse al del momento de constitución de la literatura moderna (Espectáculos).

En este ensayo, sin embargo, no me ocuparé de la literatura contemporánea sino que, a partir de un análisis del film Fotografías (2006), de Andrés Di Tella, quisiera pensar en ciertos procedimientos propios del cine documental contemporáneo en relación al modo en que surge la ficción en su interior. La expectativa es que esta indagación sirva como una base teórica para pensar las transformaciones que sufre la categoría de ficción en la literatura contemporánea y de este modo poder reflexionar, ya no sobre el cine y la literatura de un modo separado, sino sobre un tipo de narrativa o "ficción documental" que vincularía los dos medios y que se diferenciaría - no ya a partir de la especificidad mediática- sino de un cine de ficción o de una literatura de ficción entendiendo el concepto de ficción dentro de una poética clásica. ${ }^{4}$ Lo que me ocupa aquí, entonces, no es únicamente el análisis de la ambigüedad que se genera en el límite entre ficción y documental, sino el proceso y el modo en el cual surge la ficción dentro del documental mismo para poder extender este proceso a otras formas narrativas, como la literatura.

Por supuesto, la definición misma de cine documental comporta desde sus orígenes una ambigüedad en su relación con la ficción y hasta se podría decir que esta ambigüedad

3 Jacques Rancière dice, respecto a esta característica del arte contemporáneo, lo siguiente: "todas las competencias artísticas específicas tienden a salir de su propio dominio y a intercambiar sus lugares y sus poderes. Hoy tenemos teatro sin palabras y danza hablada; instalaciones y performances a modo de obras plásticas; proyecciones de video transformadas en ciclos de frescos murales; fotografías tratadas como cuadros vivientes o pintura histórica; escultura metamorfoseada en show multimedia, y otras combinaciones" (Espectador 27).

4 Más adelante me ocuparé de precisar qué entiendo por “ficción clásica”.

Revista Iberoamericana, Vol. LXXXII, Núm. 257, Octubre-Diciembre 2016, 837-854 ISSN 0034-9631 (Impreso)

ISSN 2154-4794 (Electrónico) 
es parte constitutiva misma del género. ${ }^{5}$ Sin embargo, en las últimas décadas, la labilidad en la definición de cine documental se ha vuelto aún más prominente y hoy en día es casi un lugar común de la crítica hablar de los cruces entre documentalidad y ficción en el cine documental. La inclusión de una perspectiva subjetiva y ficcional en su seno ha dado a hablar de un "giro subjetivo o afectivo" (Michael Chanan, Alicia Lebow, Michael Renov), "performativo" (Nichols), o ha contribuido a subrayar la importancia de las películas caseras (Karen L. Ishizuka y Patricia Zimmermann) o autobiográficas (Renov). Estas lecturas han relativizado cierta asociación-quizás ingenua pero no por ello menos persistente- del cine documental con un discurso objetivo, informativo, expositivo o de autenticidad para colocarlo, en cambio, en un lugar que subraya la ambigüedad, la indefinición y la reflexión sobre la propia práctica artística. Tal como sugieren Michael Renov y Elisabeth Cowie, a pesar de que haya una asociación histórica del documental con un discurso de orden científico, también se puede pensar el documental a través de una lógica del deseo o del inconsciente, no sólo por cierto "deseo de realidad" manifiesto, sino por el modo de asociación que se sigue en su narrativa. ${ }^{6} \mathrm{El}$ documental contemporáneo, entonces, le huye a una definición precisa y se mueve con una gran libertad, colocándonos muchas veces ante una incertidumbre en cuanto a su estatuto artístico o fílmico.

Como enseguida se verá, en Fotografías se cuestiona la autenticidad y la objetividad de un archivo familiar por un lado y nacional por el otro. Es este cuestionamiento el que permite que se construya, dentro del film, una dimensión ficticia. A pesar de estar centrado en un viaje del propio director al país en el que nació su madre, el film se permite reflexionar sobre diversos temas asociados a este tema central pero heterogéneos entre sí: inmigraciones, viajes, discriminación racial, identidad nacional, identidad subjetiva, relaciones familiares, diferencias culturales, memoria personal y colectiva, etc. En este trayecto, el modo en el cual surge la ficción adquiere cierta particularidad, pues ella aparece íntimamente arraigada en su génesis al documento: la ficción nace como una simulación de la documentalidad. Es decir, el filme va "documentando" hasta que surge una falla en el esfuerzo de documentación y se encuentra con algo que no se puede mostrar: un documento perdido en el archivo. Entonces se plantea un límite pues hay algo que no se puede traducir a imagen, un resto afectivo que hace agua en tanto documento. Es a partir de este hueco que la ficción nace.

Frente a un tipo de arte basado en el valor del documento -en donde se produce una anticipación del sentido- o frente un arte memorialístico o confesional, que busca

5 Recordemos, entre otras tantas, la clásica afirmación de Christian Metz: "todo filme es un filme de ficción” o la archicitada afirmación de Godard según la cual todas las películas, hasta las de ficción, son documentales de sí mismas. En casi todos los textos que intentan definir de un modo teórico el cine documental se presenta este problema.

5 Véase Renov, The Subject of Documentary xxiii.

Revista Iberoamericana, Vol. LXXXII, Núm. 257, Octubre-Diciembre 2016, 837-854 ISSN 0034-9631 (Impreso)

ISSN 2154-4794 (Electrónico) 
la expresión de un interior profundo y auténtico, en este tipo de narrativa documental (ya sea fílmica o textual), se rescata aquello que interrumpe la ambición objetiva; se subraya el valor de lo que se pierde o se olvida: una cierta disfuncionalidad, un resto improductivo, ocioso e indisciplinado. Es este exceso afectivo que se cuela como falla en el esfuerzo archivístico el que nos recuerda que, aunque estas obras parecen basar su actividad en la búsqueda de pruebas y documentos, se trata, simultáneamente, de ficciones.

\section{MOI, UN NOIR}

Con un título previo que luego modificó -"Viaje al país de mi madre"- Andrés Di Tella cuenta en Fotografias la historia de su madre, nacida en la India. La película se desarrolla a partir de dos ejes temporales. Por un lado, cuenta la migración de su madre desde la India a Buenos Aires, pasando por Londres y San Francisco, en donde la madre conoce a su padre argentino. Por el otro, desanda el camino de su madre en el presente, viajando él mismo desde Buenos Aires a la India con su mujer y su hijo, y contando su propia relación con este territorio extranjero y al mismo tiempo familiar. Mientras busca fotos en viejas cajas familiares y realiza su viaje, Di Tella (personaje de su propio filme) pone en escena las narrativas que su familia y su nación se cuentan a sí mismas, revelándolas como construcciones ficcionales y quitándoles naturalidad.

La relación con la cultura de su madre se realiza a través de un análisis tan excesivo que, por momentos, puede incluso producir cierta incomodidad. La película llega casi al colmo del subjetivismo y -respetando una marca cultural profundamente argentinapor momentos parece una sesión psicoanalítica hecha pública. Y esto no sólo por aquello que se dice (por el contenido) sino porque procede -siguiendo el modelo del viaje como "matriz vacía" propuesto por Chejfec- por pura asociación libre; ese es su método de construcción o su hechura. Así, el encanto y el interés del film está en cómo busca decir constantemente aquello que no estaba dicho. En el caso del personaje que el propio Di Tella construye para sí mismo, lo no dicho aparece como una revelación acerca de su propia identidad: "soy negro, soy WOG" (Western Oriental Gentelman). Fotografías cuenta una anécdota que marca para Di Tella el momento en el cual se dio cuenta, cuando era chico, de que era "negro": jugando con otros niños en Londres, le dicen "fucking wog" y, sin saber lo que era la palabra, advierte las caras de asco de los otros niños y se da cuenta de que se trata de un insulto terrible. Luego, a modo de revelación, encuentra en un frasco de mermelada la imagen de un niño de color junto con la palabra "gellywag" y termina de corroborar su presentimiento.

7 Esta frase de la película que se repite una y otra vez bajo diferentes formulaciones cita, evidentemente, la clásica película Moi, un noir (1958), de Jean Rouch, de la cual he tomado el título para esta sección. Evidentemetne, el film de Di Tella pretende de algún modo homenajear el documental de Rouch o al

Revista Iberoamericana, Vol. LXXXII, Núm. 257, Octubre-Diciembre 2016, 837-854 ISSN 0034-9631 (Impreso)

ISSN 2154-4794 (Electrónico) 
Una de las primeras cosas que llaman la atención de las notas que Di Tella incluye en el libro que acompaña la película y que la iluminan de un modo diferente, permitiendo una segunda lectura, es la insistencia en el problema racial. ${ }^{8}$ Este tema no ha sido trabajado de modo directo en lo que se ha escrito acerca del filme, lo cual resulta llamativo dado que Di Tella afirma la necesidad de que este sea uno de sus ejes centrales: "Hablar lo más crudamente -lo más crudamente posible- de racismo, para que conserve algo de su impacto y no sea simplemente "un tema" (Firbas y Meira Monteiro 127; énfasis mío). Pero la manera de acercarse a este tema-el tema-no es el de la denuncia, sino el de radicalizar el autoanálisis hasta mostrar que el racismo como estructura social es tan poderoso que incluso se aloja en el propio yo. En primer lugar, Di Tella explicita la ajenidad con la cual se acerca a la cultura materna, o sea, a la propia. Una de las primeras escenas con las que debía contar la película, según el guión original transcrito en el libro, era la siguiente:

Sobre el escenario kitch y berreta de un club nocturno con escenografía "latina", Amanda, una atractiva mujer de 30 años, vestida de "amante latina", al estilo de una Carmen Miranda, hace un número de strip-tease al compás de música tropical.

Andrés off: No. Ésta no es Mamá. Es Amanda. Pero hablar de Mamá es hablar de recuerdos y en los recuerdos se mezcla todo. Y quién sabe qué recuerdo tiene que ver con cuál otro... (Firbas y Meira Monteiro 114)

A pesar de que esta escena no se incluye finalmente en la película, la intención de comenzarla con una figura exótica como la de Carmen Miranda, epítome de la perspectiva turística y orientalista que aborda al otro como una mujer y un objeto sexual, es significativa y muestra su deseo de exponer el problema de un modo casi grosero y brutal. Al llegar a la India, descubre en sí mismo esta mirada: “[...] me sentí completamente ajeno, pez fuera del agua, peor que el peor turista occidental" (Firbas y Meira Monteiro 136). Pero al producirse sobre el propio yo, esta mirada se vuelve clisé de sí misma y se transforma en perspectiva crítica.

A medida que su viaje transcurre, Di Tella va hurgando en su propio pasado y reevalúa su relación con la India hasta ese momento. Se pregunta por qué su madre

menos situarse dentro de una tradición de cinéma vérité que Rouch inicia y que, según el propio Di Tella, es paradigmática en cuanto a la relación del documental con la ficción: "Para Rouch, lo que revela un documental no es 'la realidad' en sí, sino la realidad de un especie de juego que se produce entre unas personas delante -y detrás- de una cámara. Es por eso que Godard, gran admirador de Rouch, señaló a propósito de Yo, un negro que 'todo gran film de ficción tiende hacia el documental, así como todo gran documental tiende hacia la ficción"” (Firbas y Meira Monteiro 160).

8 El libro al que me refiero es editado por Paul Firbas y Pedro Meira Monteiro, Conversación en Princeton. Luego hablaré de él de modo más detallado.

Revista Iberoamericana, Vol. LXXXII, Núm. 257, Octubre-Diciembre 2016, $837-854$ ISSN 0034-9631 (Impreso) ISSN 2154-4794 (Electrónico) 
nunca le habló de su país. Su método de análisis lo lleva a reconocer la sorpresa con la que, en un momento de su vida, descubrió su propia negritud: "Cuando supe que era 'negro' fue como si me inocularan un veneno, la conciencia de no ser blanco, la 'impureza' de mi sangre, que nunca me abandonó" (Firbas y Meira Monteiro 132). O bien: "No me gustaba ser identificado como hindú. ¿O sea que yo también era racista?” (127). Así, en contra de una mirada aparentemente progresista y condescendientemente multiculturalista, Di Tella habla de su propio racismo y -paradójicamente-insistiendo sobre el poder con el cual calan los prejuicios raciales, lo revela como una estructura profundamente arraigada, incluso en su propio yo.

Pero esta constatación no se detiene en el terreno puramente privado, pues, como dice Di Tella en sus comentarios, él llega a la India por un rodeo que lo saca de su historia personal y le da a lo negado de su vida (la identidad hindú) un estatuto casi oficial o nacional. En el símbolo de identidad nacional, el gaucho, Di Tella encuentra (al igual que en su propia identidad) una herencia hindú: "También hace falta decir que llegúe a la India a través del gaucho" (Firbas y Meira Monteiro 127). Se trata de la historia de Ramachandra, que también es de la India pero que vive en la Patagonia y que es el hijo adoptivo de Ricardo Güiraldes, el mismísimo autor de Don Segundo Sombra. Toda una parte de la película está dedicada a contar el viaje de Di Tella a la Patagonia y las conversaciones que tiene con Ramachandra. Este le cuenta que hurgando y desempolvando los archivos de Güiraldes, descubrió una cantidad de documentos y notas de trabajo de su padre que relacionan el gaucho con el gurú hindú, permitiendo arrojar nueva luz a la lectura de esta novela de consolidación de la identidad nacional. En una escena de la película Ramachandra lee el famoso capítulo de la doma del caballo en esta clave.

Es decir, así como Di Tella descubre en sí una identidad hindú, también descubre en el gaucho argentino una identidad "negra". Más allá de la veracidad de esta historia, lo interesante de ella es que el gaucho como símbolo de la identidad y de la literatura "nacional" adquiere un estatuto impostado y aparece como deudor de una tradición extranjera, negra y -para la mentalidad europeizante argentina- con un grado de subalternidad mayor que la propia. Así, el archivo de Güiraldes (simbólicamente importante en un archivo literario nacional) se revela -como el archivo personal de Di Tella- como una ficción que oculta políticas racistas. Por supuesto, Ramachandra finalmente no lo hereda a Güiraldes, ya que los parientes de éste lo consideran un impostor o un intruso. En una conversación que aparece en la película, uno de los descendientes de Güiraldes le dice a Di Tella que Ramachandra era "un cuervo en una bandada de pájaros blancos" y Di Tella agrega, estableciendo un lazo entre su propia identidad y la identidad nacional: "igual que yo".

Ahora bien, a pesar de que el viaje que emprende Di Tella en Fotografías podría pensarse como una variación del tradicional viaje etnográfico, pues la primera persona viajera lo hace hacia un otro idiomático, geográfico y cultural -y no se deja de subrayar

Revista Iberoamericana, Vol. LXXXII, Núm. 257, Octubre-Diciembre 2016, 837-854 ISSN 0034-9631 (Impreso)

ISSN 2154-4794 (Electrónico) 
esta "extranjeridad" con respecto a la cultura otra-, el suyo es un caso particular en el cual la mirada turística y tradicional se complejiza, pues la cultura otra es, al mismo tiempo y sin dejar de ser exótica, propia. De este modo, la etnografía pasa a ser una suerte de autoetnografía y la separación del objeto de mirada turística y el sujeto que se propone a estudiarlo queda abolida y, simultáneamente, diferenciada: yo soy el intruso dentro de mi propia cultura (en donde el enunciado vale para los dos casos: cuando la propia cultura se refiere a Argentina así como cuando se refiere a la India). ${ }^{9}$ De este modo, si bien la película muestra las contradicciones de una mirada orientalista o exotizante, también señala la exterioridad que comportaría una crítica progresista hacia ella, al señalar la inevitabilidad de su adopción. Este acercamiento a una ajenidad a través de lo propio, o, a lo propio como si se mirara desde afuera, establece un doblez en la forma de pensar la diferencia cultural, racial o nacional. La película no deja de decir una y otra vez "soy extranjero en mi propia patria" o "ese idioma que no entiendo es en realidad mi lengua materna". La propia situación identitaria del director (y personaje) queda así en un territorio sin lengua ni patria que le recuerda al espectador todo el tiempo la falta de anclaje o de autenticidad que comporta lo identitario. Sin embargo, al exponer los deseos y los miedos más primarios de su protagonista sin ningún tipo de condenscendencia o de progresismo (¿yo también era racista?), este film no establece ningún mensaje efectivo o didáctico y no obtiene ninguna funcionalidad social.

En este movimiento, el proyecto artístico de Di Tella cuestiona la distinción entre sujeto y objeto etnográfico; entre el sujeto que filma y el objeto de documentación; entre el archivo supuestamente objetivo y el sujeto que lo estudia, o entre aquel que es nativo y el que es extrajero. Pero estos franqueamientos no se hacen de un modo puramente formal sino que surgen de una redistribución de lugares, de alteraciones de las jerarquías epistemológicas y competencias: yo hablo del otro pero ese otro soy yo. Se construye así un tipo de subjetividad en la cual se funda la posiblidad de crear una obra documental vacilante, en cuanto a la propia definición que se le da a la documentalidad. Es decir, es el cuestionamiento de la autenticidad del archivo (tanto personal como nacional) y la solidaridad que este cuestionamiento mantiene con una concepción de la subjetividad como algo opaco, los que permiten que el discurso documental en el cual el filme se desarrolla se encuentre minado en sus propios fundamentos. Es en este punto en el que la categoría de ficción adquiere una relevancia fundamental para el proyecto del documental mismo.

9 En relación al gesto “autoetnográfico” y su vínculo con un proyecto documental, ver Catherine Russel.

Revista Iberoamericana, Vol. LXXXII, Núm. 257, Octubre-Diciembre 2016, 837-854 ISSN 0034-9631 (Impreso)

ISSN 2154-4794 (Electrónico) 


\section{CONSTRUIR UN ARCHIVO PARA EL FUTURO: HACER FICCIÓN NO CONSISTE EN CONTAR HISTORIAS}

Di Tella cuenta que recibe de parte de su padre una caja con fotografías familiares que sirve como dispararador del viaje y de la película. ${ }^{10} \mathrm{El}$ filme recorre estas fotos enfocándolas muchas veces en primeros planos, de modo que pasan a ocupar la totalidad de la pantalla mientras el propio director las comenta, apuntando con el dedo a los personajes de los que se habla. Así, la película se desarrolla como si fuera una exhibición fotográfica o como un álbum de fotos comentado, característica que se enfatiza en el título y que le quita su carácter fílmico para darle una fijeza más apropiada para una obra colgada en un museo o para un libro de arte. ${ }^{11}$ Como ya se ha dicho, la película además viene acompañada de un libro, llamado Conversación en Princeton: cine documental y archivo personal, en donde, luego de una larga conversación sobre la película, Di Tella hace públicas sus notas en borrador y una suerte de guión previo a su filmación. Retomando lo que señala Daniel Link, este libro puede pensarse más que como un complemento de la película, como su "exceso", indicando que hay algo que es imposible de recuperar por entero, una memoria que está más allá de la memoria familiar e incluso -como ya se ha dicho-de la memoria nacional. ${ }^{12}$ Por otro lado, con el libro la película tiene un plus que podríamos llamar "literario" y que incrementa su deslizamiento hacia el exterior de sí misma, obligándonos a ser espectadores y lectores de un modo simultáneo, enfrentándonos a un objeto cultural múltiple, sin bordes definidos ni límites fijos. ${ }^{13}$ Este cuestionamiento de los bordes entre diversas esferas artísticas redunda en un cuestionamiento de los límites del marco principal de esta película: lo documental. Se trata de algo que excede a la obra misma, un límite que se materializa como una pérdida en la capacidad de archivar: un olvido, un documento irrecuperable o la ausencia de pruebas que puedan testimoniar un recuerdo o un sueño. Hay un resto disfuncional en relación a la intención de documentar la propia vida y -al mismo tiempo- absolutamente necesario para ser fiel a la verdad que se pretende obtener en esta documentación. De un modo paradójico, el filme parecería decir que,

${ }^{10}$ La segunda parte del subtítulo de esta sección está tomada de una frase de Jacques Rancière (Espectador 102).

11 Este aspecto es subrayado por Marcela Visconti: "La idea de estar mirando fotografías es reforzada por el sonido intermitente de un proyector de diapositivas en sincronía con sucesivos inserts negros que van puntuando el desfile de las imágenes".

12 Dice Daniel Link: "Esos textos (apuntes en una libreta, reflexiones más articuladas) son necesarios al proyecto que Di Tella encara no tanto porque lo expliquen (ésa sería su característica más débil) sino porque señalan su exceso respecto del documental: la propia memoria familiar, la que Di Tella está interrogando, es, al mismo tiempo, un viaje hacia el pozo sin fondo de las inquietantes preguntas a propósito de qué significa ser argentino y qué, ser moderno".

13 El blog que escribe Di Tella se llama también "Fotografías", de tal modo que se establece una conexión entre este blog con la película y el libro.

Revista Iberoamericana, Vol. LXXXII, Núm. 257, Octubre-Diciembre 2016, 837-854 ISSN 0034-9631 (Impreso)

ISSN 2154-4794 (Electrónico) 
sin este exceso afectivo que desborda los límites del documento o del archivo no se podría lograr el objetivo de hacer un filme documental.

En Fotografias se observa un procedimiento que es ilustrativo de esto pues las fotos reales y las filmaciones en súper 8 -provenientes de viejos archivos familiares-se superponen con otras escenas que Di Tella recuerda o fantasea sobre su madre, pero para las cuales no tiene material de archivo: ni fotos ni películas. En estos casos, el documento es reemplazado por filmaciones ficcionales en las que una actriz simula el recuerdo o inclusive un sueño que el director tiene con su madre, muchas veces dándole a la filmación contemporánea una pátina que simula la del documento histórico. Este procedimiento le permite crear retrospectivamente una experiencia o una memoria inexistente y construir -como quiere Derrida- un archivo futuro, un documento ficticio que funcionará, a partir del propio filme, como una simulación del recuerdo. Ante la imposibilidad de rescatar del olvido aquello que no sucedió, los recuerdos y los documentos que los testifican se inventan, creando una ficción dentro del universo documental. ${ }^{14}$ El valor del olvido o de la falla archivística no está en señalar un sublime irrepresentable sino en marcar la laguna que permite que la ficción ocurra. Es decir, es desde el señalamiento de una pérdida, de un agujero en el archivo, en lo identitario o en la capacidad para guardar y memorizar, que surge la misma pérdida como posibilidad subjetiva y como condición de posibilidad de lo ficticio. La ficción adquiere-entoncesciertas características particulares, pues no toma la forma de construcción verosímil (enredo, épica, drama o intriga) sino que es aquello que viene a darle voz a un exceso afectivo que no puede ser documentado de otra manera.

Este modo de entender la categoría de ficción puede quizás comprenderse mejor remitiéndose a ciertas formulaciones teóricas sobre el cine documental y sobre la

${ }_{14}$ Como ya se ha dicho, hay muchos filmes documentales que utilizan escenas ficcionales y que se ubican en el límite entre documentalidad y ficción. Sin embargo, no en todos los casos la ficción surge como invención de recuerdos o simulación de un documento de archivo. En Um Passaporte Húngaro (2002), Sandra Kogut realiza un procedimiento similar al de Di Tella. Brasileña de nacimiento, Kogut decide tramitar un pasaporte de la nacionalidad de sus abuelos, judíos expulsados de Hungría en la inminencia de la Segunda Guerra, y filma el proceso que lleva su obtensión. El documento concreto, el pasaporte de la abuela en tanto documento personal e intransferible y, al mismo tiempo, oficial y público, sirve como disparador y título, y como vértice para superponer registros y archivos públicos -como el del puerto en el que Kogut busca los registros de la llegada del barco de sus abuelos a Brasil-, y privados -como las fotos y las conversaciones filmadas con diversos miembros de la familia. Al igual que en la película de Di Tella, ante la falta de documentación que ilustre el proceso de migración de sus abuelos, Kogut coloca imágenes de estaciones de trenes y de puertos, de partidas y de llegadas, filmadas en súper 8 en el presente, pero simulando, por el tipo de cámara, imágenes de archivo y creando cierta atmósfera poética y ficcional. Así, entre medio de las charlas de Kogut con su abuela y con funcionarios estatales, es decir, en un contexto de entrevistas que nos recuerdan que estamos ante un documental, con la infiltración de las imagenes ficcionales, el filme confunde diversos registros artísticos y dos temporalidades, pues con ellas se construye un pasado y se comenta, simultáneamente, sobre la situación migratoria de la propia directora y sobre su regreso al país de origen como extranjera.

Revista Iberoamericana, Vol. LXXXII, Núm. 257, Octubre-Diciembre 2016, 837-854 ISSN 0034-9631 (Impreso)

ISSN 2154-4794 (Electrónico) 
fotogafía. En un ensayo en el que analiza un filme de Chris Marker, Jacques Rancière propone que en el trabajo que realiza el filme documental en tanto género se puede ver cómo la categoría de ficción se reduce a "su esencia":

El filme documental puede entonces aislar el trabajo artístico de la ficción disociándolo de eso a lo que se acostumbra a asimilar: la producción imaginarioa de verosimilitudes y efectos de realidad. Puede reducirlo a su escencia: un modo de descomponer la historia en secuencias o montar planos en forma de historia, de unir y desunir voces y cuerpos, sonidos e imágnes, de dilatar o comprimir el tiempo. (Fabula 183)

Es decir, la disociación del concepto de ficción de la construcción de una verosimilitud-cuya correspondencia pertenece según Rancière a una poética clásica-nos lleva a pensarlo de un modo tal que lo retrotrae a su sentido etimológico: "La primera acepción de fingere no es 'fingir' sino 'forgar'” (Fabula 182). En otros ensayos en los que vuelve sobre el mismo asunto, Rancière insiste en que el trabajo de la ficción "no consiste en contar historias" (Espectador 102), y en que su definición no debería basarse en la oposición entre "la realidad y sus apariencias" (102), sino más bien en la posiblidad de ver lo mismo de un modo diferente o de construir otras formas de dar sentido. En esta misma línea podría entenderse la hipótesis de Josefina Ludmer acerca de la definición de la ficción en la época de la autonomía de la literatura a partir de una relación específica entre "la historia" y "la literatura", en la cual ambas esferas mantienen su especificidad y separación:

La narración canónica, o del boom [Cien años de soledad, por ejemplo] trazaba fronteras nítidas entre lo histórico como "real" y lo "literario" como fábula, símbolo, mito, alegoría o pura subjetividad, y producía una tensión entre los dos: la ficción consistía en esa tensión. La "ficción" era la realidad histórica [política y social] pasada [o formateada] por un mito, una fábula, un árbol genealógico, un símbolo, una subjetividad o una densidad verbal. ("Literaturas posautónomas")

Por el contrario, si pensamos la ficción fuera de una "poética clásica" o fuera de la autonomía, se hace necesario tener en cuenta la imposibilidad de separar estas esferas y, por lo tanto, la relación de la ficción con el documento (o el referente). En relación a esta concepción sobre la ficción y a su íntima relación con el trabajo documental, resulta iluminador un ensayo del fotógrafo catalán Joan Fontcuberta llamado, justamente, "Ficciones documentales". Fontcuberta deconstruye allí lo que califica como el "discurso hegemónico de la modernidad fotográfica", según el cual la esencia de la fotografía residiría en su capacidad de significación indicial y en su "voluntad de testimonio" (104). Según Fontcuberta, a pesar de que a lo largo de la historia de la fotografía ha prevalecido una intención descriptiva, esta misma intención se ha valido, en muchas ocasiones, de lo que él califica como una "trampa", ya que involucra la urdimbre de una

Revista Iberoamericana, Vol. LXXXII, Núm. 257, Octubre-Diciembre 2016, 837-854 ISSN 0034-9631 (Impreso)

ISSN 2154-4794 (Electrónico) 
ficción. A través del análisis de uno de los primeros daguerrotipos conocidos -la vista del Boulevard du Temple (fechado en 1838)-y de una imagen de Hippolyte Bayard de 1840 en el que el autor de la foto se retrata a sí mismo simulando haberse suicidado, Fontcuberta descubre -"en el mismo nacimiento de la fotografía" (104)-la trampa que cuestiona, al mismo tiempo que instituye, el estatuto de la foto como documento. La imagen de Daguerre es doble, dos tomas efectuadas en el mismo día. En una de ellas se ve el boulevard completamente vacío en un horario en el que debería estar lleno de gente. Fontcuberta explica que esta incompatibilidad entre la realidad y la percepción de la cámara ocurre porque el tiempo de exposición que requería la obtención de la imagen en ese entonces no permitía captar ningún objeto en movimiento. La solución de Daguerre a este problema -que se ve en la segunda toma- es la de utilizar actores e introducir un limpiabotas con su cliente sobre la vereda. De esta manera, engañando al espectador a través de una actuación, consigue una imagen más fiel a la realidad. Ahora bien, según señala Fontcuberta, mientras "el estatuto ficcional de ese daguerrotipo presupone que la intervención en la escena pasa desapercibida al espectador" (107), en el caso de la imagen de Bayard, la simulación de su propio suicidio "no esconde la naturaleza ficcional de la imagen" (108). Surge entonces, "otro tipo de ficción" (109), que me interesa particularmente para pensar en relación al modo en el cual surge la ficción en Fotografias:

La podríamos denominar ficción lúdica o ficción artística, categorías que se caraterizarían frente a la ilusión cognitiva y a la manipulación en que se anuncian siempre como ficción, no camuflan su naturaleza de simulación. La ficción artística no es que se oponga a lo verdadero, sino que se opone tanto a lo verdadero como a lo falso (entendido lo falso como error o mentira). Tampoco se opone al discurso referencial y realista sino que coloca al referente entre paréntesis. No afecta la verdad o falsedad de un enunciado, sino a nuestra facultad de creer, o sea, a nuestra facultad de adherirnos a proposiciones que consideramos verdaderas (lo sean o no). (109; énfasis mío)

La ficción artística o lúdica entonces correspondería a un tipo de simulación de un documento que no esconde su naturaleza ficcional. Así, si según Rancière en el cine documental podemos encontrar la ficción en un estado de "pureza", a través del ensayo de Fontcuberta se ve muy claro cómo en el nacimiento de la fotografía y, por lo tanto, en el origen mismo del documento -entendido con mayúscula- se encuentra una ficción. Sin embargo, en ambos planteos se rechaza la idea de que por tratarse de una ficción su valor de verdad disminuya. Por lo contrario, como dice Fontcuberta, la "ficción artística" coloca al referente "entre paréntesis" y promueve nuevos modos de colocarse ante la obra.

Quizás es en este sentido que puede entenderse la afirmación de Di Tella según la cual en sus filmes documentales le interesa exponer el "fracaso del proyecto documental"

Revista Iberoamericana, Vol. LXXXII, Núm. 257, Octubre-Diciembre 2016, 837-854 ISSN 0034-9631 (Impreso) 
(Firbas y Meira Monteiro 42), en donde "documental" aquí debería leerse como sinónimo de "discurso objetivo" o "testimonial"; como un género con un propósito informativo y didáctico, con un fin moral o de denuncia. En un texto llamado "La palabra 'documental", Di Tella alude al rechazo que le provoca la palabra "documental" y a la posibilidad de pensarla de un modo diferente:

No me gusta la palabra documental. Es como el club de Groucho: "No deseo pertenecer a un club que acepta entre sus socios a alguien como yo". El vocablo documentalista trae a la mente un auxiliar administrativo que revisa expedientes en una dependencia municipal. $\mathrm{O}$, en el mejor de los casos, una especie de cazador filantrópico que avista ballenas (o indígenas) con un teleobjetivo. En algún sentido, el documental parece ubicarse en un polo opuesto al del cine. "Cine" evoca toda una sucesión de palabras que empiezan con f de ficción: fantasía, fábula, fascinación, frenesí, fantasma, felicidad, film. "Documental", en cambio, trae otra serie de asociaciones, términos que empiezan con t de testimonio: tema, trabajo, tesis, teoría, tarea, tristeza... tedio. Sin embargo, ay, hago documentales. Pero creo que el documental, sin perder la fuerza de lo real, también puede aspirar a esa dimensión cinematográfica propia de la ficción. Es decir, me gusta pensar que hago películas. (énfasis mío)

Así como en el concepto de "ficción artística o lúdica" propuesto por Fontcuberta se pone el referente entre paréntesis permitiendo un acceso a la verdad a través de la simulación, este modo de entender lo documental permite que no se pierda "la fuerza de lo real", pero que, se acceda, simultáneamente, a una dimensión que aparece asociada a cierto más allá del documento mismo y que Di Tella nombra como especificidad del cine: "hago películas". Se trata de una práctica más relacionada con el exceso, con el deseo o con el arte ("fantasía, fábula, fascinación, frenesí, fantasma, felicidad, film") que lo que a primera vista entendemos cuando escuchamos la palabra "documento". La opción documental entendida en este sentido desborda el puro testimonio y la "tristeza, el trabajo o el tedio" asociados con la pretensión de objetividad. Se trata de una suspensión moral que cancela cualquier tipo de expectativa previa acerca de lo que debe ser tal o cual práctica artística o, en este caso preciso, de lo que debe ser el cine documental. ${ }^{15}$ Pero la libertad que otorga el documental no es únicamente en

\footnotetext{
15 En este mismo sentido "excesivo" es que debe pensarse el gesto autobiográfico en los filmes de Di Tella, como cancelando una expectativa previa de lo que debe o no debe ser una práctica artística: "Es muy difícil en el discurso del documental renunciar a esa idea de la utilidad [...] Las películas caseras serían como el colmo de lo que no tiene interés ni utilidad pública. Por supuesto yo creo que es al revés, que hacer público lo privado es de gran ultilidad pública. Pero cuesta que esa idea sea aceptada. Siempre hay como un reproche, como si en el documental lo privado fuera menos serio, irresponsable, narcisista" (Firbas y Meira Monteiro 121). Este gesto de darle una "utilidad" o -podríamos decir-sentido a aquello que parece ser aparentemente sin sentido, se ve en la noción de que el documental autobiográfico puede ser un acto de responsabilidad: "An autobiographical documentary is a courious act of responsibility. I
}

Revista Iberoamericana, Vol. LXXXII, Núm. 257, Octubre-Diciembre 2016, 837-854 ISSN 0034-9631 (Impreso)

ISSN 2154-4794 (Electrónico) 
relación a la supuesta objetividad del "documento" sino también a la estructura que brindaría la ficción diseñada de un modo clásico, a través de la construcción de una verosimilitud que mantiene una separación clara entre "literatura" e "historia". En el mismo texto recién citado, Di Tella habla de la diferencia entre cine de ficción y documental en estos términos:

Se ha dicho que en la ficción se escribe antes de filmar (el guión) mientras que en el documental se escribe después de filmar (el montaje). Se trata sin duda de una simplificación. Yo creo, más bien, que cualquier distinción remitiría a las diferentes tradiciones, o "familias", de películas. Esa caracterización ayuda, de todos modos, a explicar la potencia actual de la corriente documental dentro del cine argentino.

La ficción depende demasiado de la imaginación del que escribe el guión, de sus limitaciones, de sus prejuicios, incluso de los estereotipos genéricos de un argumento. La escritura de un documental, del buen cine documental, refleja la experiencia, siempre singular, siempre imprevisible, de una investigación, de un rodaje, de un encuentro con el mundo. El resultado, si no ha de traicionar el proceso, no puede ser otra cosa que único. En el documental están las historias que un guionista difícilmente pudo imaginar. ("Palabra 'documental"')

Esta improvisación que señala Di Tella como propia del cine documental y como algo opuesto al cine de ficción, en el que el guión se escribe antes de filmar, coincide con algo de lo que señala Chejfec en el texto arriba citado sobre el viaje: se trata de una narrativa que no esconde el proceso mismo de escritura y en la que, tal como en el cine documental, se elige un punto de partida - una investigación, dice Di Tella; una "matriz vacía" decía Chejfec-como excusa para reflexionar sobre diversos temas que se asocian de un modo imprevisible, siguiendo una imaginación que la estructura de la ficción clásica parecería restringir en lugar de fomentar. Cine-literatura ensayo o cine-literatura documental, entonces, pero no en el sentido de que busque una prueba objetiva sobre un tema específico, sino en el sentido de que busca ensayar un cierto modo de imaginación e imagina -así- algo que no se hubiera podido prever dentro de la estructura ficcional clásica, algo que se escapa.

Es así que a partir del "fracaso" del "proyecto documental" entendido como puro documento surgen nuevas posiblidades para el cine, pero también para la literatura o para cualquier otra forma narrativa. "Documental” sería entonces un modo de narración o de imaginación en el que la ficción surge sin plan, como colándose entre los resquicios

assume responsibility for this story. I answer for it with my life. I answer for my ideas about film and art (and life) with my own life. I lay down my own body there, with no surrogates. And of course, in so doing, I confess my limitations" (DiTella, "Curious Inicident" 36). Esto podría pensarse en relación a las observaciones que propone Judith Butler en Giving an Account of Oneself.

Revista Iberoamericana, Vol. LXXXII, Núm. 257, Octubre-Diciembre 2016, 837-854 ISSN 0034-9631 (Impreso) ISSN 2154-4794 (Electrónico) 
del archivo pero en íntima relación a este (en íntima relación al documento). Se trata de un "fuera de campo" que, como dice Jean-Louis Comolli, cuestiona la noción de que todo es pasible de ser archivado, procesado o pasible de transformarse en imagen y relaciona la obra con el "cine" (entendiendo este concepto como lo hace Di Tella en el pasaje arriba citado pero también como lo entiende Comolli, es decir, como aquello que se opone al espectáculo). ${ }^{16}$ Pareciera, según esta idea, que el cine documental y la literatura que se le parece, tienen una capacidad para crear un espacio de redistribución de lo sensible, de inoperatividad, o una "zona ciega" (Montaldo) que abre nuevas posibilidades para contar una historia. Se trata de un sitio que surge desde un revés, como un recuerdo inventado o una desmemoria que se transforma, al convertirse en texto o en imagen, en contra-memoria, en la medida en la que escribe -nuevamente- algo de la historia y permite -como dice Rancière a propósito del trabajo de la ficción- "un paisaje nuevo de lo posible" (Espectador 103).

En uno de los textos que acompañan la película, Di Tella cuenta una conversación que tuvo con el escritor de origen indio Naipaul, en la cual le preguntó por su viaje a Londres en los años cincuenta -época en la que también estaban allí su padre y su madre: una pareja interracial-. Naipaul le cuenta que en ese momento él no estaba interesado en la ola inmigratoria del momento y se lamenta por haberse perdido "el fenómeno humano y social tan extraordinario que estaba delante de sus ojos" (Firbas y Meira Monteiro 109). A partir de esto, Di Tella comenta:

Eran los comienzos de ese gran movimiento de personas que hoy se ve reflejado en la población de cualquier ciudad europea o norteamericana. Ya no se trataba simplemente de europeos que se mudaban a América, como pudo ser la inmigración de principios de siglo en Estados Unidos o incluso la Argentina, sino gente de todos los continentes y todas las razas que iba a todas partes. Era el principio del presente, dijo Naipaul. (Firbas y Meira Monteiro 110)

A partir del comentario de Naipaul, en el cual se subraya un anacronismo, Di Tella propone un modo de entender el pasado en el cual este no se erige como historia cerrada, como origen o autenticidad. Es que, según él demuestra en su filme, los recuerdos también se inventan y son esos los que servirán como achivos futuros, produciendo un resto afectivo, excesivo a lo histórico o a lo estrictamente documental. Es esta perspectiva genealógica que deja un lugar para que el afecto se infiltre, y para

16 "Mostrar que no se puede mostrar todo es poner al espectador en un lugar real con respecto a la ilusión de totalidad del Espectáculo. En el cine se trata de mostrar, contra el espectáculo, que el mundo no es 'omnivisible', que ver es ver más allá del encuadre, ver que hay un fuera de campo que no está encuadrado. El fuera de campo no es únicamente lo que el encuadre oculta al mostrar, es todo lo que se mantiene al margen de la posiblidad de ver, al margen del lugar del espectador, lo que no constituye imagen (y por lo tanto no hace espectáculo), el fuera de campo de toda imagen" (127, énfasis mío).

Revista Iberoamericana, Vol. LXXXII, Núm. 257, Octubre-Diciembre 2016, 837-854 
que se pueda leer el pasado como un resultado de lo que ocurre en el presente, la que le da a la obra su potencia crítica y le permite producir una intervención en su propio mundo contemporáneo.

\section{OBRAS CITADAS}

Bizzio, Sergio. Borgestein. Buenos Aires: Mondadori, 2012.

Butler, Judith. Giving an Account of Oneself. New York: Fordham UP, 2003.

Comolli, Jean-Louis. Cine contra espectáculo. Seguido de técnica e ideología (19711972). Buenos Aires: Manantial, 2010.

Cowie, Elizabeth. "The Spectacle of Actualtiy." Collective Visible Evidence. J. Gaines y M. Renov, eds. Minneapolis: U of Minnesota P, 1999.

Chanan, Michael. The Politics of Documentary. London: British Film Institute, 2007. Derrida, Jacques. Archive Fever: A Freudian Impression. Chicago: U ofChicago P, 1995. Di Tella, Andrés. "The Curious Incident of the Dog in the Nighttime." The Cinema of Me. The Self and Subjectivity in First Person Documentary. A. Lebow, ed. New York: Columbia UP, 2012.

"La palabra 'documental"”. Página 12. 28 jun. 2012. <www.pagina12.com.ar/ diario/suplementos/espectaculos/5-25666-2012-06-28.html>. 8 sept. 2016.

Erlan, Diego. "Quería escribir una novela sin sujeto". Entrevista a Sergio Bizzio. Revista N. Clarín. 24 nov. 2012.

Firbas, Paul y Pedro Meira Monteiro, eds. Conversación en Princeton. Andrés Di Tella: cine documental y archivo personal. Buenos Aires: Siglo XXI, 2006.

Fontcuberta, Jean. "Ficciones documentales". La cámara de Pandora. La fotografía después de la fotografía. Barcelona: Gustavo Gili, 2010. 103-10.

Franco, Jean. The Decline and Fall of the Lettered City. Cambridge: Harvard UP, 2002. García Canclini, Néstor. La sociedad sin relato. Buenos Aires: Katz, 2010.

Garramuño, Florencia. La experiencia opaca. Buenos Aires: Fondo de Cultura Económica, 2009.

Hounie, Analía. "Noticias de un narrador cavilante: entrevista con Sergio Chejfec". Diario Perfil. 17 June 2007. <http://www.diarioperfil.com.ar/edimp/0181/articulo. php?art=2708\&ed=182>. Último acceso en noviembre de 2011.

Ishizuka, K y P. Zimmermann, eds. Mining the Home Movie: Excavations in Histories and Memories. Berkeley: U of California P, 2007.

Laddaga, Reinaldo. Espectáculos de realidad: ensayo sobre la literatura latinoamericana de las últimas dos décadas. Rosario: Beatriz Viterbo, 2007.

Estética de la emergencia. Buenos Aires: Adriana Hidalgo, 2006.

Lebow, Alicia, ed. The Cinema of Me. The Self and Subjectivity in First Person Documentary. New York: Columbia UP, 2012.

Revista Iberoamericana, Vol. LXXXII, Núm. 257, Octubre-Diciembre 2016, 837-854 ISSN 0034-9631 (Impreso)

ISSN 2154-4794 (Electrónico) 
Levrero, Mario. El discurso vacío. Barcelona: Mondadori, 2010.

Link, Daniel. 2006. Blog linkillo. <http://linkillo.blogspot.com/2006/08/librosrecibidos_18.html>. 30 ago. 2013.

Ludmer, Josefina. Aquí América Latina. Una especulación. Buenos Aires: Eterna Cadencia, 2010.

"Literaturas posautónomas". Ciberletras. Revista de Crítica Literaria y de Cultura. 17 julio 2007. <www.lehman.cuny.edu/ciberletras/v17/ludmer.htm>.

Metz, Christian. Le Signifiant imaginaire: psychanalyse et cinema. Paris: Union génerale d'editions, 1977.

Montaldo, Graciela. Zonas ciegas. Populismo y experimentos culturales en Latinoamérica. Buenos Aires: Fondo de Cultura Económica, 2010.

Rancière, Jacques. El espectador emancipado. Buenos Aires: Manantial, 2010. La fabula cinematográfica. Barcelona: Paidos, 2005.

Renov, Michael. The Subject of Documentary. Minneapolis: U of Minnesota P, 2004.

Russel, Catherine. Experimental Ethnography: The Work of Film in the Age of Video. Durham: Duke UP, 1999.

Um Passaporte Húngaro. Sandra Kogut, dir. 2002.

Visconti, Marcela. "El principio del presente". Revista Afuera. 10 mayo 2011. <http:// www.revistaafuera.com/articulo.php?id=139\&nro=10>. 30 nov. 2011. 
